\title{
Evaluación positiva de medicamentos: junio y julio 2014
}

\author{
Sánchez López P. ${ }^{1}$, Cabanes Mariscal MA. ${ }^{2}$, Tabakov A. ${ }^{3}$, García Luque A. ${ }^{4}$ \\ Sanid. mil. 2014; 70 (4): 279-281; ISSN: 1887-8571
}

\section{RESUMEN}

Se reseñan los medicamentos ya evaluados por la Agencia Española de Medicamentos y Productos Sanitarios hechos públicos en junio, julio y agosto de 2014, y considerados de mayor interés para el profesional sanitario. Se trata de opiniones técnicas positivas que son previas a la autorización y comercialización del medicamento.

PALABRAS CLAVE: Daclatasvir, Daklinza ${ }^{\circledR}$, Abacavir/Dolutegravir/Lamivudina, Triumeq $^{\circledR}$, Tobramicina, Vantobra ${ }^{\circledR}$, oxidróxido de hierro polinuclear, Velphoro ${ }^{\circledR}$, Ibrutinib, Imbruvica ${ }^{\circledR}$, Delalisib, Zydelig ${ }^{\circledR}$.

Positive assessment of drugs: June and July of 2014

SUMMARY: the drugs assessed by the Spanish Agency for Medicines and Health Products made public in June, July and August of 2014, and considered of interest to the healthcare professional, are reviewed. These are positive technical reports prior to the authorization and placing on the market of the product.

KEY WORDS: Daclatasvir, Daklinza ${ }^{\circledR}$, Abacavir/Dolutegravir/Lamivudina, Triumeq ${ }^{\circledR}$, Tobramicina, Vantobra ${ }^{\circledR}$, oxidróxido de hierro polinuclear, Velphoro ${ }^{\circledR}$, Ibrutinib, Imbruvica ${ }^{\circledR}$, Delalisib, Zydelig ${ }^{\circledR}$.

\section{DACLATASVIR (DAKLINZA $\left.{ }^{\circledR}\right)^{1-3}$}

Se trata del primer agente antiviral directo que actúa inhibiendo el complejo de replicación NS5A del Virus de la Hepatitis $\mathrm{C}$ (VHC), inhibe tanto la replicación del ARN como el ensamblaje del virión.

El Ensayo pivotal principal que evaluó la eficacia y seguridad de Daclastavir ${ }^{3}$, lo hizo en 211 adultos; los pacientes del estudio estaban infectados con los genotipos 1, 2 o 3, y todos recibieron tratamiento durante un periodo de 12 ó 24 semanas. La mayoría de los pacientes no habían recibido tratamiento previo para la hepatitis $\mathrm{C}$, aunque algunos presentaban infección por el genotipo 1 resistente a las medicaciones habituales, consistentes en telaprevir o boceprevir (también denominados inhibidores NS3/4A) en combinación con peginterferón alfa y ribavirina.

Alrededor del $99 \%$ de los pacientes con infección por el genotipo 1 (125 de 126), el $96 \%$ de los pacientes con infección por el genotipo 2 (25 de 26) y el $89 \%$ de pacientes con infección por

${ }^{1}$ Cte. Farmacéutico.

${ }^{2}$ Tcol. Farmacéutico.

Servicio de Farmacia Hospitalaria.

${ }^{3}$ MIR.

${ }^{4}$ Cte. Médico.

Servicio de Farmacología Clínica.

Hospital Central de la Defensa Gómez Ulla. Madrid. España.

Dirección para correspondencia: psanlo8@oc.mde.es

Recibido: 1 de octubre de 2014

Aceptado: 22 de octubre de 2014 el genotipo 3 (16 de 18) consiguieron la erradicación del virus 12 semanas después de finalizar el tratamiento planificado para ellos y por tanto la curación de la hepatitis C crónica.

Daclatasvir está indicado, en combinación con otros medicamentos, para el tratamiento de la infección crónica por virus de la hepatitis C (VHC) en adultos (ver secciones 4.2, 4.4 y 5.1 de la ficha técnica). Para la actividad específica según el genotipo del virus de la hepatitis $\mathrm{C}$ (VHC), ver secciones 4.4 y 5.1 de la ficha técnica. Se presenta en comprimidos recubiertos con película de 30 y $60 \mathrm{mg}$.

La combinación de medicamentos utilizada y la duración del tratamiento dependerá del genotipo del virus de la hepatitis $\mathrm{C}$ con el que el paciente esté infectado y del tipo de problemas hepáticos que padezca.

Las reacciones adversas más comunes observadas durante el desarrollo clínico cuando se usa en combinación fueron: fatiga, cefalea y náuseas.

\section{ABACAVIR/DOLUTEGRAVIR/LAMIVUDINA $\left(\text { TRIUMEQ }{ }^{\circledR}\right)^{1,4-6}$}

La indicación aprobada de Triumeq ${ }^{\circledR}$ es el tratamiento de adultos y adolescentes mayores de 12 años de al menos $40 \mathrm{Kg}$ de peso infectados por el virus de inmunodeficiencia humana (VIH). Se presenta en comprimidos recubiertos (50, 600 y 300 $\mathrm{mg})$.

Es una combinación de tres antirretrovirales: Dolutegravir inhibe la integrasa del VIH uniéndose al sitio activo de la integrasa y bloqueando la transferencia de la cadena durante la 
integración del ácido desoxirribonucléico (ADN) retroviral, que es esencial para el ciclo de replicación del VIH. Abacavir y lamivudina son sustratos e inhibidores competitivos de la transcriptasa inversa del VIH y su actividad antiviral principal tiene lugar mediante la incorporación de la forma monofosfato en la cadena del ADN viral, terminando la misma.

La evaluación positiva se basa en los resultados de dos estudios pivotales, el estudio fase III de dolutegravir SINGLE $\left(\right.$ ING114467) ${ }^{5}$, en adultos no tratados previamente, realizado con dolutegravir y abacavir/lamivudina por separado, y un estudio de bioequivalencia (ING114580) ${ }^{6}$, de la combinación a dosis fija de estos tres compuestos con su administración por separado.

En el primero, un ensayo de no inferioridad con una análisis de superioridad preespecificado, hubo más pacientes que se mantuvieron indetectables (ARN VIH- $<50$ copias $/ \mathrm{mL}$ ) en el brazo con dolutegravir y abacavir/lamivudina (los componentes de Triumeq ${ }^{\circledR}$ por separado) que en el brazo de Atripla ${ }^{\circledR}$, de Gilead, que combina efavirenz, emtricitabina y tenofovir y es el régimen en un solo comprimido más utilizado.

La diferencia fue estadísticamente significativa y cumplió el test de superioridad preespecificado, y fue impulsada por una mayor tasa de discontinuación debido a eventos adversos en el brazo de Atripla ${ }^{\circledR}$.

A las 96 semanas, el 80 por ciento de los pacientes que recibieron el régimen que incluía dolutegravir mantuvieron la supresión virológica comparado con el 72 por ciento de los pacientes que recibieron Atripla ${ }^{\circledR}$, y las reacciones adversas al tratamiento (grados 2-4) más frecuentes fueron insomnio (3\%), cefalea (2\%) y fatiga $(2 \%)$.

Antes de iniciar el tratamiento de pacientes con infección por VIH con medicamentos que contengan abacavir, se debería llevar a cabo en ellos una prueba para detectar la presencia del alelo HLA-B*5701, independientemente del origen racial de los mismos pues Abacavir no debe prescribirse a pacientes que se sabe son portadores del alelo HLA-B*5701.

\section{TOBRAMICINA 170 MG, SOLUCIÓN PARA INHALACIÓN POR NEBULIZACIÓN (VANTOBR $\left.A^{\circledR}\right)^{1}$}

Está indicado en el control de la infección pulmonar crónica por Pseudomonas aeruginosa en pacientes desde los 6 años en adelante con fibrosis quística que no toleran la inhalación de tobramicina en polvo seco.

El principio activo es tobramicina, un aminoglucósido que afecta a la síntesis de la proteína bacteriana lo que se traduce en una rápida acción bactericida dependiente de la concentración.

Este medicamento es una solución para nebulización que ha mostrado una disminución sustancial del tiempo de inhalación junto con la posibilidad de poder utilizarse como alternativa terapéutica en los pacientes con fibrosis quística e infecciones pulmonares crónicas por P.aeruginosa que no toleran la inhalación de tobramicina en polvo seco.

Las reacciones adversas más comunes observadas durante el desarrollo clínico fueron: tos y disfonía.

Vantobra fue designado como un medicamento huérfano el 27 de febrero de 2009.

\section{MEZCLA DE OXIHIDRÓXIDO DE HIERRO POLINUCLEAR (III), SACAROSA Y ALMIDON $\left(\text { VELPHORO }^{\circledR}\right)^{1,7}$}

Está indicado en el control de los niveles séricos de fósforo en pacientes adultos con insuficiencia renal crónica (IRC) en hemodiálisis (HD) o diálisis peritoneal (DP).

Se trata de una mezcla de oxihidroxido de hierro (III) polinuclear, sacarosa, y almidón también conocida como oxihidroxido sucroférrico, el cual se usa para el tratamiento de la hiperfosfatemia en comprimidos masticables de $500 \mathrm{mg}$. La unión del fosfato tiene lugar gracias al intercambio de ligandos entre los grupos hidroxil y/o el agua y los iones fosfatos a través de los valores de $\mathrm{pH}$ fisiológico del tracto gastrointestinal. Los niveles séricos de fósforo se reducen al reducirse la absorción de fosfatos en la dieta.

El Ensayo Clínico pivotal (PA-CL-03A) 7 demostró que Velphoro ${ }^{\circledR}$ reduce los niveles séricos de fosforo en pacientes con diálisis de mantenimiento con un perfil de seguridad aceptable de acuerdo a los datos disponibles de un año de duración.

Dicho estudio demostró que Velphoro controla con éxito la hiperfosfatemia con menos comprimidos que carbonato de Sevelamer, el actual tratamiento estándar en pacientes con insuficiencia renal crónica en diálisis.

Las reacciones adversas más comunes observadas durante el desarrollo clínico fueron: alteraciones en el sabor y alteraciones gastrointestinales. La gran mayoría de estos efectos ocurrieron al principio del tratamiento y disminuyeron con el tratamiento continuado.

\section{IBRUTINIB (IMBRUVICA $\left.{ }^{\circledR}\right)^{8,9}$}

Está indicado para el tratamiento del linfoma de células del manto (LCM) en pacientes resistentes al tratamiento o tras recaída. También está indicado para el tratamiento de la leucemia linfocítica crónica (LLC) en pacientes adultos que han recibido al menos un tratamiento previo, o en primera línea en pacientes con deleción 17 p o mutación TP53 no candidatos para quimioinmunoterapia.

El principio activo es ibrutinib, un agente antineoplásico, el cual inhibe la tirosina quinasa de Bruton, una molécula de señalización del receptor del antígeno de la célula-B y las vías del receptor de citoquina.

La opinión positiva del CHMP se basó en datos de los estudios de fase II (PCYC-1104) $)^{9}$ en LCM y fase III RESONATE(TM) (PCYC-1112-CA) ${ }^{9}$ y Fase II (PCYC-1102) ${ }^{9}$ en LLC.

Las reacciones adversas más comunes observadas durante el desarrollo clínico fueron: neumonía, infección del tracto respiratorio superior, sinusitis, neutropenia, trombocitopenia, anemia, mareos, dolor de cabeza, hemorragia, hematomas, petequias, diarrea, vómitos, estomatitis, nauseas, estreñimiento, erupción cutánea, artralgia, dolor musculoesquelético, pirexia y edema periférico.

Ibrutinib fue designado medicamento huérfano el 26 de abril de 2012 para el tratamiento del linfoma de células del manto (LCM) y el 12 de marzo de 2013 para el tratamiento de la leucemia linfocítica crónica (LLC). 


\section{IDELALISIB $\left(Z Y D E L I G^{\circledR}\right)^{8,10}$}

Está indicado en combinación con rituximab para el tratamiento de pacientes adultos con leucemia linfocítica crónica (LLC) que hayan recibido al menos un tratamiento previo, o en primera línea de tratamiento de pacientes con la deleción $17 \mathrm{p} \mathrm{o}$ la mutación TP53, no candidatos para quimio-inmunoterapia. También está indicado como monoterapia para el tratamiento de pacientes adultos con linfoma folicular (FL) que son refractarios a dos líneas previas de tratamiento.

El principio activo es idelalisib, un agente antineoplásico que inhibe la fosfatidilinositol 3 kinasa p110 delta (PI3Kdelta), la cual es hiperactiva en tumores de células B, y es fundamental para multiplicar las vías de señalización que impulsan la proliferación, la supervivencia, localización, y la retención de células malignas en los tejidos linfoides y en la medula ósea.

La evaluación positiva para LLC viene respaldada por los datos de un estudio de Fase 3 randomizado, doble ciego, controlado por placebo (GS-US3120116) de idelalisib más rituximab en 220 pacientes adultos con LLC recurrente que no podrían tolerar la quimioterapia estándar. El estudio se interrumpió a principios de octubre de 2013 por un Comité de Control de Datos independiente debido a una ventaja estadísticamente significativa en la SLP en el grupo de idelalisib y en comparación con el grupo que solo estaba recibiendo rituximab $(\mathrm{RR}=0,18$ (95\% IC: $0,10,0,32), \mathrm{p}<0,0001)$.

La aprobación acelerada por la FDA de idelalisib para FL, el tipo más común de linfoma no-Hodgkin indolente, está respaldada por los datos de un estudio de Fase II de grupo único (GS-1101) de monoterapia de idelalisib en pacientes refractarios a rituximab y a una quimioterapia con un agente alquilante.

Las reacciones adversas más comunes observadas durante el desarrollo clínico fueron: infecciones, neutropenia, aumento de transaminasas, elevación de triglicéridos, diarrea/colitis, erupción y pirexia.

\section{BIBLIOGRAFÍA}

1. Agencia Española de Medicamentos y Productos Sanitarios. Informe mensual sobre Medicamentos de Uso Humano y Productos Sanitarios Junio 2014. Disponible en: http://www.aemps.gob.es/informa/boletinMensual/2014/junio/boletin-junio.htm

2. Committee for Medicinal Products for Human Use (CHMP).Daclatasvir. Disponible en: http://www.ema.europa.eu/docs/en_GB/document_library/ EPAR_-_Public_assessment_report/human/003768/WC500172849.pdf

3. Sulkowski MS, Gardiner DF, Rodriguez-Torres M, Reddy KR, Hassanein T, Jacobson I et al. Daclatasvir plus sofosbuvir for previously treated or untreated chronic HCV infection. N Engl J Med.2014;370(3):211-21.

4. Ficha técnica de Triumeq ${ }^{\circledR}$ disponible en: http://www.accessdata.fda.gov/ drugsatfda_docs/label/2014/205551s000lbl.pdf

5. Walmsley SL, Antela A, Clumeck N et al; Dolutegravir plus abacavir-lamivudine for the treatment of HIV-1 infection. N Engl J Med. 2013;369(19):18071818.

6. Weller S, Chen S, Borland J et al. Bioequivalence of a Dolutegravir, Abacavir and Lamivudine Fixed-Dose Combination Tablet and the Effect of Food. JAIDS. Disponible en: http://journals.lww.com/jaids/Abstract/publishahead/ Bioequivalence_of_a_Dolutegravir,_Abacavir_and.97920.aspx

7. Center for drug evaluation and research..FDA Summary review. Disponible en: http://www.accessdata.fda.gov/drugsatfda_docs/nda/2013/205109Orig1s000 SumR.pdf

8. Agencia Española de Medicamentos y Productos Sanitarios. Informe mensual sobre Medicamentos de Uso Humano y Productos Sanitarios Julio 2014. Disponible en: http://www.aemps.gob.es/informa/boletinMensual/2014/julio/ boletin-julio.htm

9. Center for drug evaluation and research..FDA Medical review. Disponible en: http://www.accessdata.fda.gov/drugsatfda_docs/nda/2013/205552Orig1s000 MedR.pdf

10. Committee for Medicinal Products for Human Use (CHMP).Idelalisib. Disponible en: http://www.ema.europa.eu/docs/en_GB/document_library/ EPAR_-_Public_assessment_report/human/003843/WC500175379.pdf 